\title{
Autosomal dominant asymmetrical radial dysplasia, dysmorphic facies, and conductive hearing loss (facioauriculoradial dysplasia)
}

\author{
A E HARDING, ${ }_{\ddagger}^{+}$C M HALL, $\dagger$ AND M BARAITSER $\dagger$ \\ From*the MRC Clinical Genetics Unit, Institute of Child Health, and \\ $\dagger$ the Hospital for Sick Children, Great Ormond Street, London
}

SUMMARY A syndrome characterised by asymmetrical radial dysplasia, dysmorphic facies, conductive deafness, and external ear deformity is described in a mother and her daughter. This combination of anomalies has previously been reported in members of a single family. The disorder appears to be clinically and genetically distinct from others associated with radial dysplasia, such as Nager's acrofacial dysostosis and the lachrimoauriculoradiodental syndrome. Inheritance is autosomal dominant, with marked variation in expression of the mutant gene.

The birth frequency of defects of the radius or radial rays is estimated as 1 in $30000 .^{1}$ Carroll and Louis ${ }^{2}$ found that $77 \%$ of 53 patients who had attended hospital with radial dysplasia had associated anomalies of other organ systems and that this was more common if there was bilateral upper limb deformity. Radial dysplasia has been observed as a feature of a large number of syndromes, ${ }^{3}$ but autosomal dominant radial dysplasia with deformities of the pinna, middle ear, and facial dysmorphism has only previously been reported in one family. ${ }^{4}$ The subject of the present paper is a similar family, in which expression of the mutant

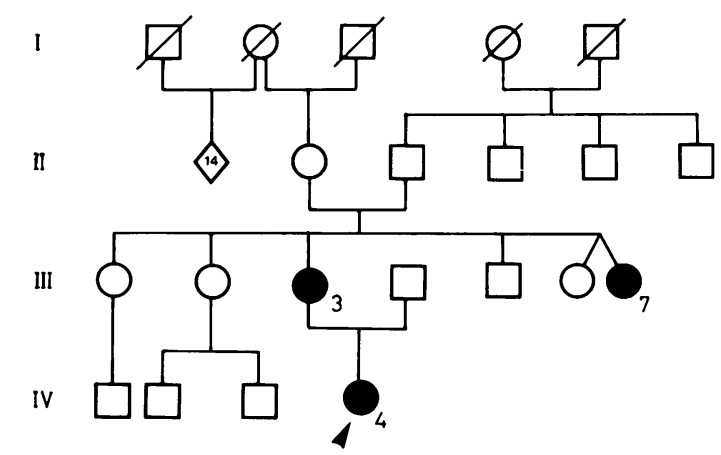

FIG 1 Pedigree of family.

Received for publication 13 July 1981

$\ddagger$ Present address: Department of Neurology, The Middlesex Hospital, Mortimer Street, London W1N 8AA. gene was very variable. In addition, there were associated skeletal anomalies in the spine and lower limbs. The pedigree of the family is shown in fig 1 .

\section{Case reports}

All persons in generations I and II were stated to have no upper limb deformity or hearing loss but none was available for study.

\section{3}

This 23-year-old female was noted to have bilateral upper limb deformities at birth. She had had surgery to the left wrist and hand at the age of 14 . There were no symptoms of hearing loss.

On examination she was of normal intelligence. Her height was $136 \mathrm{~cm}$ (below the 3 rd centile) and occipitofrontal head circumference was $55.5 \mathrm{~cm}$ (50th centile). There was no clinical evidence of deafness and the pinnae were normal.

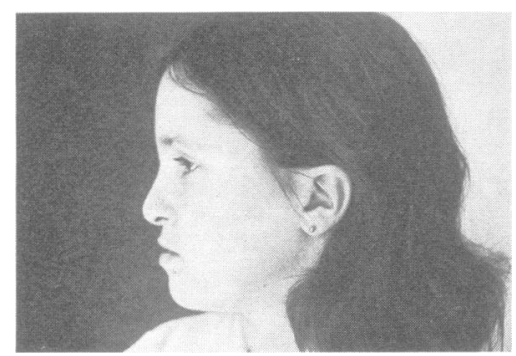

FIG 2 Case III.3 showing mild mid-facial depression. 
The stapedial reflex was absent bilaterally. Audiometry was normal. The facial appearance suggested mild maxillary hypoplasia (fig 2 ). There was marked deformity of both upper limbs which was more severe on the left (fig 3). On the right the thumb and thenar eminence were absent. There was a flexion contracture of the index finger. On the left, there was dislocation of the shoulder. The forearm was considerably shortened and the thumb, index finger, and thenar eminence were absent. The lower limbs were clinically normal.

Radiological examination demonstrated severe upper limb shortening on the left with dislocation at the shoulder and elbow joints. The radius was absent (fig 4). There was no ossification of the thumb and only a rudimentary second metacarpal. The changes on the right were relatively mild with

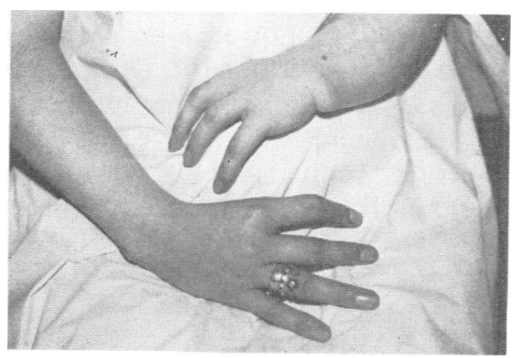

FIG 3 Case III.3 showing bilateral upper limb deformity and shortening, more marked on the left. Both thumbs and the left index finger are absent.

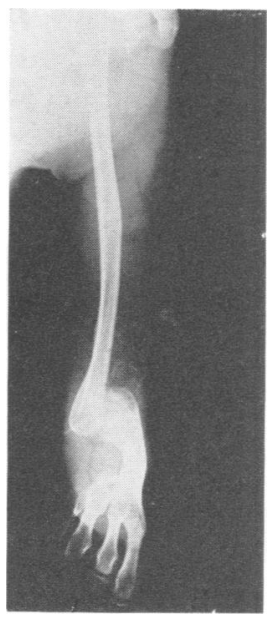

FIG 4 AP radiograph of left arm. There is dislocation at the shoulder and elbow. The radius is absent and there is shortening and bowing of the ulna. The thumb is absent. The second metacarpal is rudimentary and its phalanges absent. synostosis of the proximal radius and ulna (fig 5). Both fibulae were hypoplastic with proximal shortening (fig 6). Apart from a defect in the neural arch of L5, the spine was normal (fig 7).

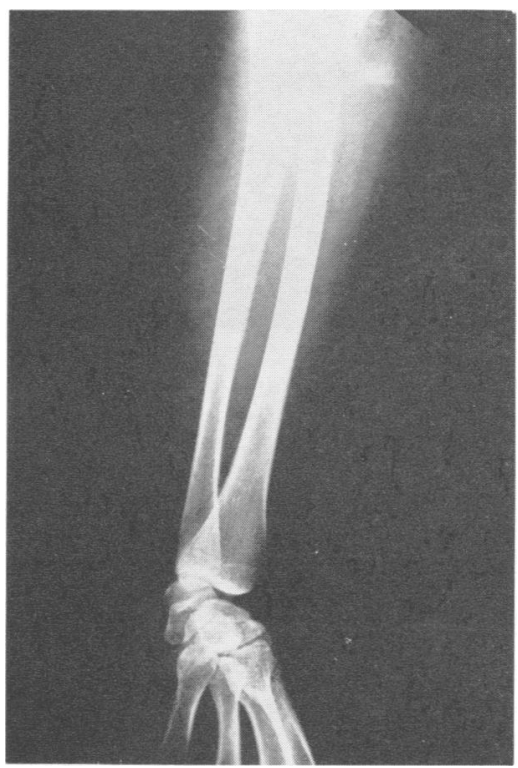

FIG 5 AP radiograph of the right forearm. There is bony synostosis of the proximal third of the radius and ulna. The thumb is absent.

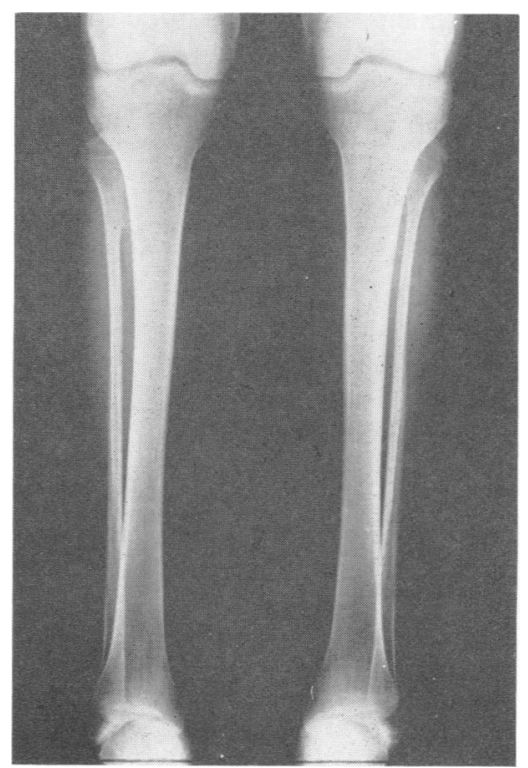

FIG 6 AP radiograph of both legs. There is proximal shortening and hypoplasia of both fibulae, with an exostosis of the proximal fibular metaphysis on the left. 


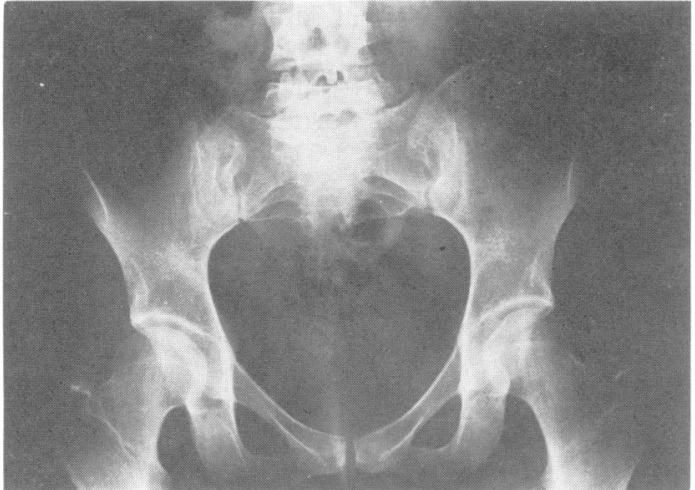

FIG 7 AP radiograph of the pelvis. The femoral heads are not well covered by the acetabular roofs. There is a defect of the right neural arch of L5.

\section{7}

This 17-year-old female refused examination but was known to have had a rudimentary thumb on the left hand which was removed in the neonatal period. She was said to be partially deaf in the left ear.

IV.4 (PROBAND)

This 3-year-old female was found to have bilateral upper limb deformity at birth. Motor milestones were normal. At the age of one year she did not appear to respond to sound, and clinical testing at that stage suggested bilateral deafness. At the time of examination she had not begun to speak but made occasional noises which were understood by her mother.

On examination she was thought to be of normal intelligence but had no intelligible speech. Her head

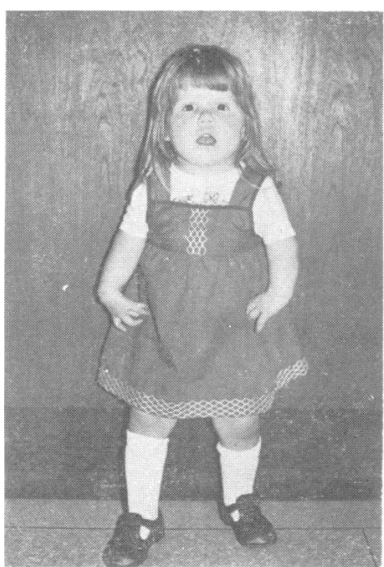

FIG 8 Case IV.4 showing facial features similar to those of III.3 with a long philtrum. There is bilateral mesomelic shortening of the arms and rudimentary or absent thumbs . circumference was $48.5 \mathrm{~cm}$ (50th centile) and her height was $65.5 \mathrm{~cm}$ (below the $3 \mathrm{rd}$ centile). She had a similar facial appearance to her mother (fig 8), with mid-facial depression, a short nose, and in addition a long philtrum and a metopic frontal suture. The left pinna was normal but the right was primitively formed (fig 9). Free field hearing tests suggested a considerable degree of deafness which was more marked on the right. She reacted by turning to moderately high-level intensity test sounds and localised the source reasonably well. Audiometry was impossible because of poor co-operation.

There were bilateral reduction deformities of the forearms, which were more marked on the left, and bilateral club hand deformity. The thumbs were rudimentary and arose from the axial border of the iv index fingers. There was fixed flexion of the right ring and little fingers and the left index and ring fingers. Genu varus was noted.

Radiological examination showed long clavicles with lateral upward convexities (fig 10). On the left the radius was absent and the thumb markedly hypoplastic (fig 11). There was shortening and synostosis of the right radius and ulna with no ossification of the thumb (fig 12). Unusual changes

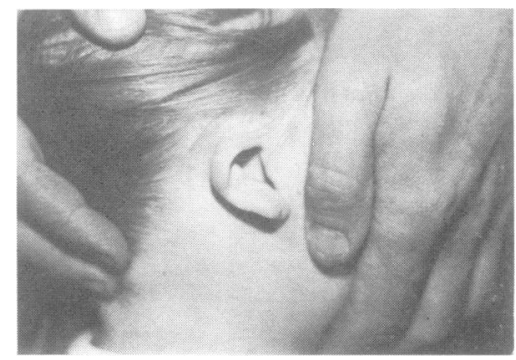

FIG 9 Case IV.4 The pinna is primitively formed.

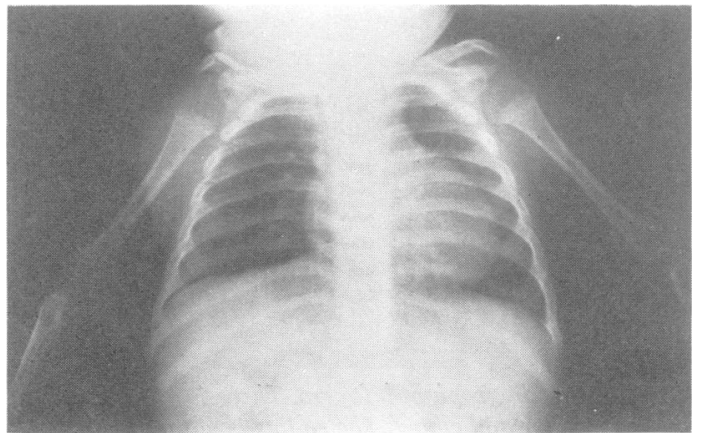

FIG 10 AP radiograph of the chest. The clavicles are abnormally high and long with upward convexities of their lateral thirds. 


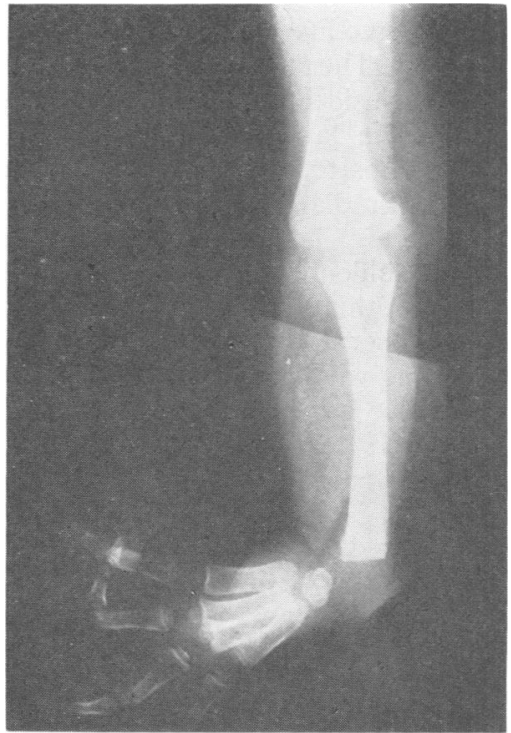

FIG 11 AP radiograph of the left forearm. The radius is absent and the ulna short. There is virtually no ossification of the thumb. There is a flexion deformity at the proximal interphalangeal joint of the middle finger.

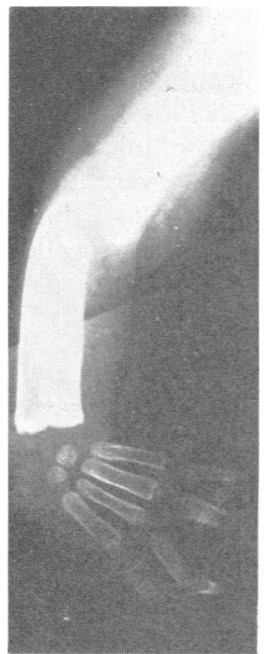

FIG 12 AP radiograph of the right forearm. There is total synostosis of the shortened radius and ulna. There is no ossification of the thumb and flexion deformities are present at the proximal interphalangeal joints of the index and ring fingers.

were present in the lumbar spine (fig 13); the lumbar vertebral bodies were fused anteriorly and there was mild posterior wedging. There was no radiological abnormality of the lower limbs.

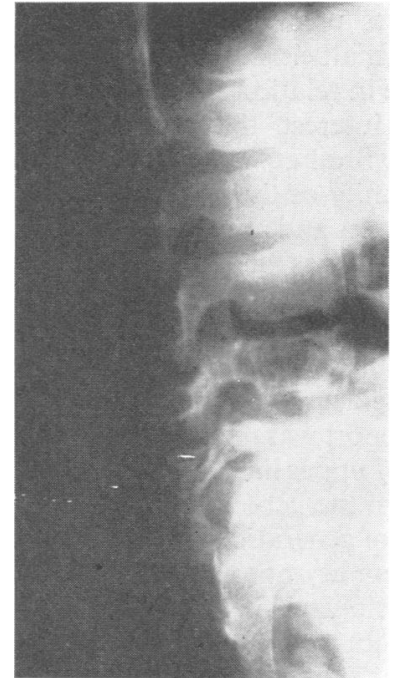

FIG 13 Lateral lumbar spine. There is anterior fusion of the vertebral bodies of L1-L4 associated with some posterior wedging.

\section{Discussion}

The family reported here have the same syndrome as that described by Stoll et $a l^{4}$ in a father and son. The former was relatively short $(1.65 \mathrm{~m})$. He had bilateral deformities of the pinnae, more marked on the left, with external auditory canal stenosis on that side. Hearing was absent in the left ear. On the right the antihelix was enlarged but hearing was normal. The philtrum was long and prominent. The nose was somewhat bulbous and the bridge flattened, along with the rest of the mid-face. There was severe bilateral upper limb deformity; both forearms were rudimentary. The thumbs and index fingers were absent.

Both humeri were hypoplastic and the radii absent. There were only three carpal and metacarpal bones. On the right, two of the latter articulated with a single digit. There was an additional proximal and middle phalanx on the left.

The patient's son had a similar facial appearance. The external ears were said to be abnormal. The left stapes and oval window were absent, with associated conductive hearing loss. Hearing on the right was normal. The left arm was the same as his father's but three digits were present on the right.

Stoll et al ${ }^{4}$ noted that both of these subjects had sinus arrhythmia and considered this to be a part of the syndrome, but the electrocardiographs presented do not appear to be pathological. Sinus arrhythmia was more marked in the son, as would be expected. ${ }^{5}$ 
Both patients presented here had normal electrocardiographs, albeit showing physiological variation of heart rate in relation to respiration.

It is of interest that the facial dysmorphism observed by Stoll et $\mathrm{al}^{4}$ was similar to that reported here. Deformity of the pinna was less prominent in one of our cases and absent in one. However, hearing loss in IV.4 was marked, resulting in delayed development of speech, which was not the case in the family of Stoll et al. Asymmetry, both of deafness and upper limb deformity, was present in both families. The degree of phocomelia in the previously published report was more severe than that described here. In III.7 upper limb deformity was minimal. The expression of the gene varied considerably as one of the parents of generation III must have been affected, but both were asymptomatic.

The radiological findings in the spine and lower limbs were not presented in the report of Stoll et al. ${ }^{4}$ Both of the patients studied here had vertebral anomalies and one had hypoplastic fibulae. Radial dysplasia is not commonly associated with malformations of the lower limbs. These may be found in the VATER syndrome, Roberts syndrome, and in some cases of sirenomelia. ${ }^{3}$

The radiological appearance of the clavicles in case IV.4 is of interest. This lateral 'clavicular hook' may be seen in other conditions associated with radial dysplasia, such as the Holt-Oram syndrome. ${ }^{6}$

The most important syndromes in which orofacial malformation and radial dysplasia occur are the lachrimoauriculoradiodental (LARD) syndrome, ${ }^{78}$ the orocraniodigital syndrome, ${ }^{9}$ and Nager's acrofacial dysostosis. ${ }^{10}$ The characteristic features of the LARD syndrome are congenital absence of the lachrimal apparatus, cup-shaped ears associated probably with abnormalities of the middle ear, hypodontia, and variable radial defects. Levy? described a sporadic case, but Hollister et $a^{8}$ reported transmission of the disorder by a male to five of his eight children. Neither of the patients observed here had any disturbance of lachrymation or dentition. These features were fully penetrant in the cases of the LARD syndrome described to date.

The Juberg-Hayward syndrome is probably of autosomal recessive inheritance. It comprises bilateral or unilateral cleft lip/palate, mild microcephaly, broad nasal bridge, and radial dysplasia of varying degree. Nager's acrofacial dysostosis has been reported in about 13 patients. ${ }^{3}$ Affected sibs were described by Walker. ${ }^{11}$ Inheritance is therefore probably autosomal recessive. The features of mandibulofacial dysostosis are downward slanting palpebral fissures, hypoplasia of the mandible, deformed ears with conductive deafness, macrostomia, malformations of the palate, and colobomata of the lower eyelids. A tongue-like extension of the hair on the cheek is common. The facial features reported have, however, varied considerably, as has the degree of radial dysplasia. The latter has ranged from hypoplasia of the thumbs to radioulnar synostosis with elbow deformity or radial phocomelia.

Radial defects have also been observed in three sporadic cases of the Goldenhar syndrome. ${ }^{12-14}$ The characteristic features of this syndrome are unilateral epibulbar dermoids, upper lid colobomata and malformations of the pinna with preauricular tags and fistulae with mandibular hypoplasia. The vertebral anomalies are variable. ${ }^{13}$ Most cases are sporadic, but affected sibs ${ }^{15}{ }^{16}$ and parent to child transmission have been observed.

The syndrome described in this report, and that of Stoll et $a l,{ }^{4}$ appears to be distinct. Inheritance is clearly autosomal dominant, but with very variable expression. The mutant gene concerned has fairly wide ranging effects on the maturation of the limb buds and vertebral column. The facial and external and internal ear anomalies are presumably the result of failure of development of the second branchial $\vec{\oplus}$ arch, as most of the pinna and the stapedius are ? derivatives of this structure, ${ }^{18}$ as is the maxilla. It is of interest in this respect that case III.3 had bilaterally absent stapedial reflexes without any hearing loss.

The variable expression of the mutant gene $\frac{}{\Phi}$ producing facioauriculoradial dysplasia is of importance in genetic counselling. It should be possible to detect moderate or severe upper limb deformity fetoscopically. Nevertheless, this may not be highly correlated with severe hearing loss which is potentially the major source of disability in affected subjects.

We wish to thank Dr L Fisch and Mr T Johnson for performing the audiological investigations.

\section{References}

1 Birch-Jensen A. Congenital deformities of the upper extremities. Copenhagen: Munksgaard, 1949.

2 Carroll RE, Louis DS. Anomalies associated with radial dysplasia. J Pediatr 1974;84:409-11.

3 Temtamy S, McKusick V. The genetics of hand malformations. Birth Defects 1978 ;XIV.

4 Stoll C, Levy JM, Frankfort JJ, Roos R, Rohmer A. N L'association phocomelie-ectrodactylie, malformations $\omega$ des oreilles avec surdité, arythmie sinusale. Arch Fre Pediatr 1974;31:669-80.

5 Schamroth L. An introduction to electrocardiography. 5th ed. Oxford: Blackwell, 1976.

6 Igual M, Giedion A. The lateral clavicular hook: its? objective measurement and its diagnostic value in Holt-Oram syndrome, diastrophic dwarfism, thrombo- $\frac{}{\Phi}$ cytopenia absent radius syndrome and trisomy 8. Ann Radiol (Paris) 1979;2-3:136-41.

7 Levy WJ. Mesoectodermal dysplasia. A new combination of anomalies. Am J Ophthalmol 1967;63:978-82. 
8 Hollister DW, Klein SH, Hendrick J De J, Lachman RS, Rimoin DL. The lacrimo-auriculo-dento-digital syndrome. J Pediatr 1973 ; 83: 438-44.

9 Juberg RC, Hayward JR. A new familial syndrome of oral, cranial and digital anomalies. J Pediatr 1969;74:755-62.

10 Nager FR, de Reynier JP. Das Gehororgan bei den angeborenen Kopfmissbildungen. Pract Oto-RhinoLaryng (Basel) 1948;10, suppl 2:1-128.

11 Walker FA. Apparent autosomal recessive inheritance of the Treacher Collins syndrome. Birth Defects 1974; $\mathbf{X}(\mathbf{8}): 135-7$.

12 Essen-Moller E. Uber aneborenen Radius defekt, Ohrdefekt, Facialislahmungen anlasslich eines Falles von multiplen Missbildungen. $Z$ Menschl Vererb $u$ Konstit Lehre 1929;14:52-68.

13 Gorlin RJ, Jue KL, Jacobsen U, Goldschmidt E. Oculoauriculovertebral dysplasia. J Pediatr 1963;63:991-9.
14 Mandelcorn MS. Goldenhar's syndrome and phocomelia. Case report and etiologic considerations. Am J Ophthalmol $1971 ; 72: 618-21$.

15 Proto F, Scullica L. Contributo allo studio della ereditaria die dermoidi epibulbari. Acta Genet Med Gemellol (Roma) 1966;15:351-63.

16 Krause U. The syndrome of Goldenhar affecting two siblings. Acta Ophthalmol 1970;48:494-9.

17 Summitt RL. Familial Goldenhar syndrome. Birth Defects 1969;V(2):106-9.

18 Nager GT. Congenital aural atresia: anatomy and surgical management. Birth Defects 1971 ;VII(IX):33-51.

Requests for reprints to Dr A E Harding, Department of Neurology, The Middlesex Hospital, Mortimer Street, London W1N 8AA. 